\title{
Experimental Study of Ablation Processes of SiC-based Materials in Air Plasma Freejets
}

\author{
By Masato FunAtsu ${ }^{1)}$, Masahiro OzawA ${ }^{1)}$, Hiroyuki ShIRAI ${ }^{2)}$ and Fumio TAKAKUSAGI ${ }^{3)}$ \\ ${ }^{1)}$ Graduate School of Engineering, Gunma University, Kiryu, Japan \\ ${ }^{2)}$ The Open University of Japan, Maebashi, Japan \\ 3) School of Engineering, Gunma University, Kiryu, Japan
}

(Received July 12th, 2009)

\begin{abstract}
Ablation experiments of $\mathrm{SiC}$ were performed in air plasma freejets at an atmospheric pressure to investigate its ablation properties, weight loss and weight loss rate. The heat flux and temperature were adjusted by changing distance of a test piece from a nozzle exit. The properties of carbonaceous materials were also measured and were compared with SiC. It was found that the properties of $\mathrm{SiC}$ were significantly different from those of the carbonaceous materials. A shape of the ablated test piece of $\mathrm{SiC}$ was almost the same as the carbonaceous test piece, but its surface was partially covered with a whitish deposit. From surface observations with a SEM and an optical microscope, and chemical analyses with an EPMA, it was estimated to be $\mathrm{SiO}_{2}$.
\end{abstract}

Key Words: SiC-based Materials, Ablation Processes, Air Plasma Freejets, High-enthalpy Flows, Thermal Protection Systems

Nomenclature

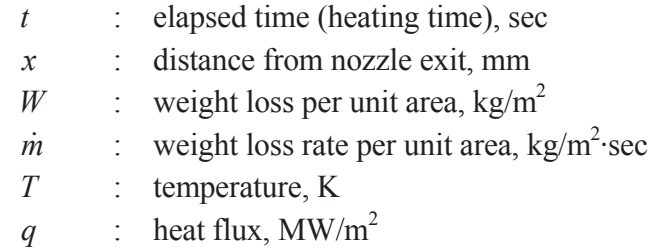

\section{Introduction}

When a spacecraft enters the atmosphere of the Earth or other planets at a hypervelocity, an extremely strong shock wave is formed over the vehicle. The vehicle is heated by convection and radiation from high temperature plasmas in the shock layer. In order to protect the vehicle from this heating effectively, more detailed understanding of physicochemical properties of high temperature plasmas and of thermal protection systems are required. One of the representative thermal protection systems is an ablation method $^{1)}$. As an ablation material, carbonaceous material has been studied for a long time and put into practical use $\mathrm{e}^{2,3)}$.

Besides the carbonaceous materials, advanced ceramics and its composite materials must be a possible candidate as an ablation material ${ }^{4,5)}$. However, investigations for these materials have not been enough to this day. Especially, the behavior of ablation in high-enthalpy flows, in addition to the ablation properties of the materials, has not been fully understood.

In our laboratory, ablation experiments of SiC-based and carbonaceous materials had been conducted systematically mainly by using air plasmajets and air plasma freejets ${ }^{6-9)}$. The heat-resistance experiments were mainly conducted by using the air plasmajets. It was found that weight loss of SiC-based materials was much smaller than that of carbonaceous materials ${ }^{8}$. But the heat of ablation of $\mathrm{SiC}$ was not measured correctly in these experiments. For better understanding of fundamental ablation properties of SiC-based and carbonaceous materials, it was thought that ablation experiments have to be performed under various temperature conditions. To do this, air plasma freejets were generated by putting a 2nd-nozzle as an anode outside of the plasma torch of the micro-air plasmajet generator. Ablation experiments by thus generated air plasma freejets could be performed for fairly wide temperature conditions.

In this study, ablation experiments of $\mathrm{SiC}$ were performed by the air plasma freejets in order to investigate the fundamental properties of $\mathrm{SiC}$ as an ablation material, and also carbon and carbon/carbon composite material for comparison. In the experiments, weight loss and weight loss rate for each material were measured for several elapsed times and for several distances from nozzle exit, and the results were compared with each other. In addition, the ablated surface of $\mathrm{SiC}$ test piece was observed in detailed microscopically with a scanning electron microscope (SEM) and an optical microscope, and was analyzed chemically with an electron probe micro-analyzer (EPMA) for understanding the change of state of $\mathrm{SiC}$. Based upon these results, the influence of the change of state of $\mathrm{SiC}$ to weight loss and weight loss rate was discussed.

\section{Experimental Setup}

Figure 1 shows a schematic view of experimental setup of ablation experiments ${ }^{9}$. The experimental setup was made up 


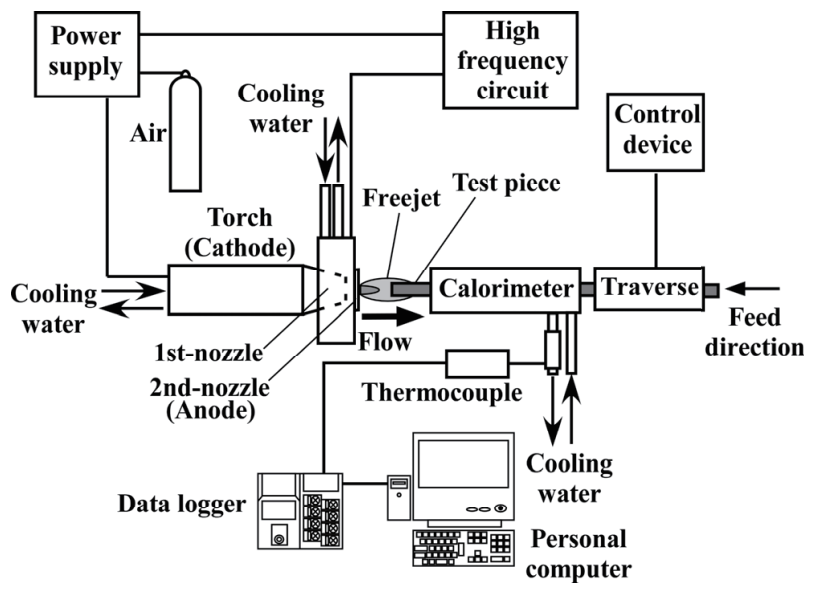

Fig. 1. Schematic view of experimental setup of ablation experiments.

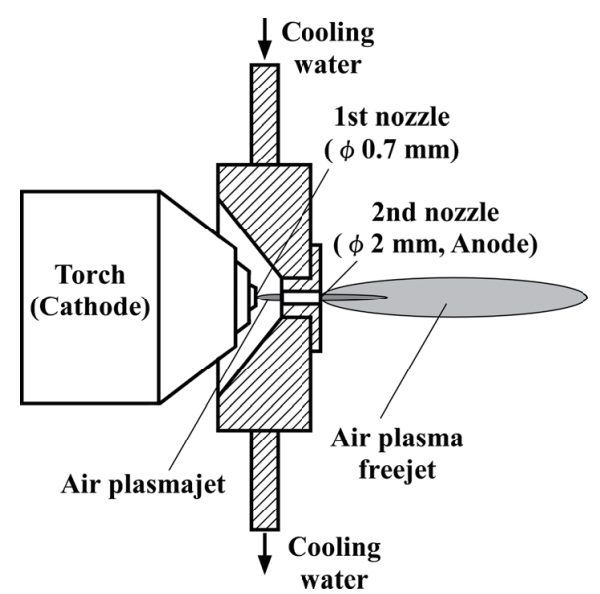

Fig. 2. Schematic view of nozzle layout of plasma freejets generator.

of an air plasma freejets generator, a calorimeter and an automatic test piece positioning control system. Figure 2 shows a schematic view of nozzle layout of the plasma freejets generator. The air plasma freejets generator had a cathode in the torch and an exit nozzle (1st-nozzle). The 2nd-nozzle, which worked as an anode outside of the torch, was installed just downstream of the 1st-nozzle. Air arc-heated between the 1st- and 2nd-nozzles, was discharged out of the 2nd-nozzle to form a plasma freejet. The exit diameters of the 1st-nozzle and 2nd-nozzle were $0.7 \mathrm{~mm}$ and $2.0 \mathrm{~mm}$, respectively. The distance between the electrodes was $3.0 \mathrm{~mm}$. Discharge current was set $10 \mathrm{~A}$, discharge voltage $160-175 \mathrm{~V}$, reservoir pressure $0.6 \mathrm{MPa}$, and ambient pressure $0.1 \mathrm{MPa}$ (atmospheric pressure). Heat flux was calculated from temperature elevation of cooling water flowing in the calorimeter. The calorimeter of triplex annular type worked as a test piece holder, too. Test pieces were set on a flow axis of the air plasma freejets. Distance from the 2nd-nozzle exit to the tip of the test piece was controlled by using an automatic test piece positioning control device to keep a required distance, because a position of the test piece tip changed due to its melting and vaporizing.

Test pieces used in this experiment were a circular cylinder of silicon carbide ( $\mathrm{SiC}$ ), which is $\alpha-\mathrm{SiC}$, of $2 \mathrm{~mm}$ in diameter

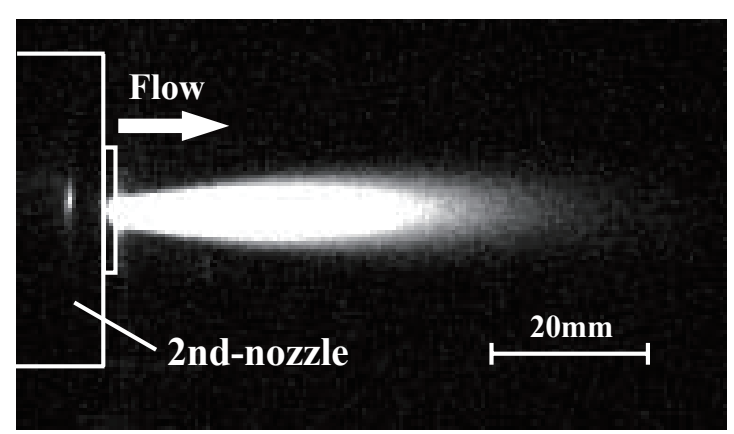

Fig. 3. CCD image of air plasma freejet.

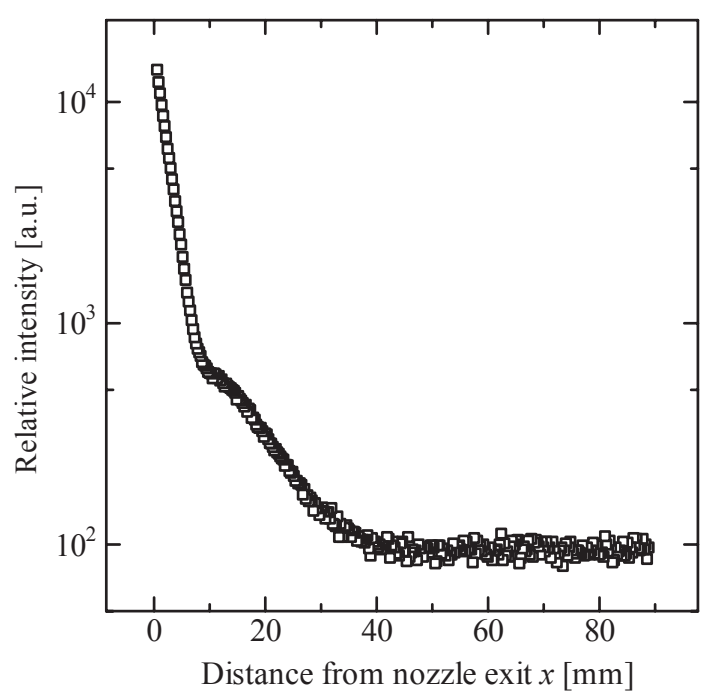

Fig. 4. Relationship between relative intensity and distance from nozzle exit.

and $100 \mathrm{~mm}$ in length, and carbon $(\mathrm{C})$ which is graphite and carbon/carbon composite material $(\mathrm{C} / \mathrm{C})$, both a square cylinder of $2 \mathrm{~mm}$ on a side and $100 \mathrm{~mm}$ in length. Weights of test pieces before and after ablation experiments were measured by a high precision electronic balance, not continuously during heating. SEM image acquisition and chemical analysis of the test pieces were conducted by an EPMA, and surface observations by an optical microscope.

In the previous study at our laboratory, the distributions of radiative intensity, cold wall heat flux, and stagnation temperature in the air plasma freejet were meaured ${ }^{9}$. Experimental setup and experimental conditions were almost the same as in the present experiments. The cold wall heat flux of the plasma freejet were measured by a calorimeter in the same way as the present case, but its configuration was of double annular type. The temperatures of the plasma freejet were measured by a thermocouple. The radiative intensity distribution was measured by a CCD camera.

\section{Thermal Properties of Air Plasma Freejets}

Figure 3 shows a CCD image of the air plasma freejet. Here, the bright plume is a plasma freejet. The freejet was generated by a rapid expansion of a high-temperature gas from the 


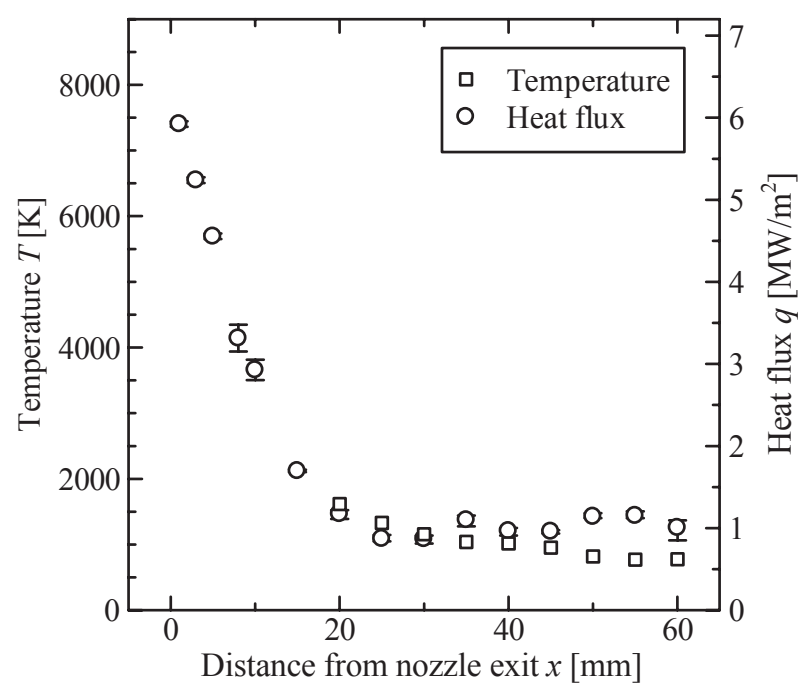

Fig. 5. Temperature and heat flux profiles of air plasma freejet.

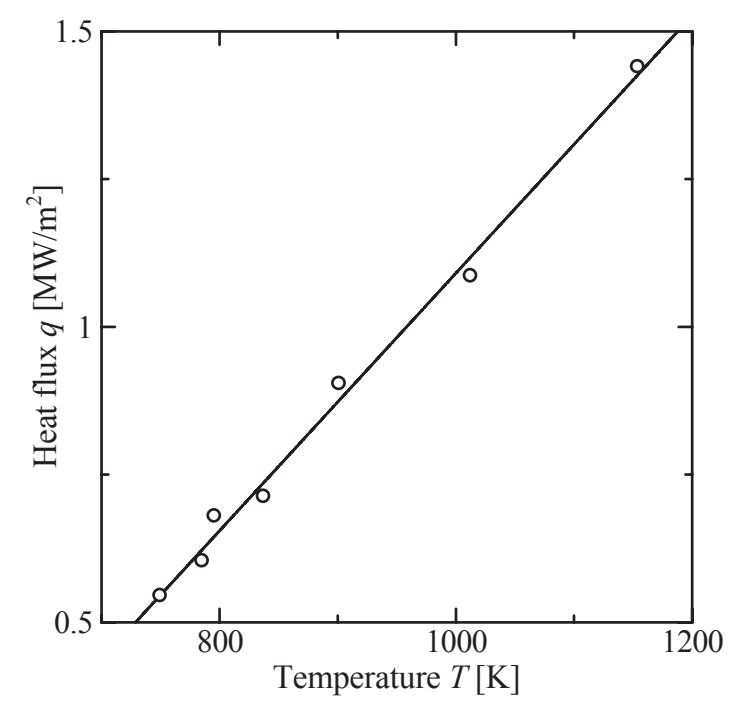

Fig. 6. Relationship between temperature and heat flux.

2nd-nozzle exit. The radiation intensity of the freejet changes greatly, axially and radially. Figure 4 shows the profile of relative intensity along an axial line of the plasma freejet shown in Fig. 3. The intensity decreases drastically to $7 \mathrm{~mm}$ from nozzle exit, and then the decrease become moderate at the distance of $7 \mathrm{~mm}$ to $40 \mathrm{~mm}$. There was virtually no radiation in a downstream region of $40 \mathrm{~mm}$, that is, the radiant region of the air plasma freejet was about $40 \mathrm{~mm}$ in length in the flow direction. Figure 5 shows cold wall heat flux and stagnation temperature distributions on the center axis of the freejet, here the horizontal axis is a distance from the nozzle exit in common. The temperature was measurable in the range of $20 \mathrm{~mm}$ to $60 \mathrm{~mm}$ from the nozzle exit, because in the upstream region flow temperature was too high for the thermocouple used. The heat flux was measured at many points between $1 \mathrm{~mm}$ and $60 \mathrm{~mm}$. To calculate the heat flux, Eq. (1) was used.

$$
q=\rho_{w} C_{p} f \Delta T / A
$$

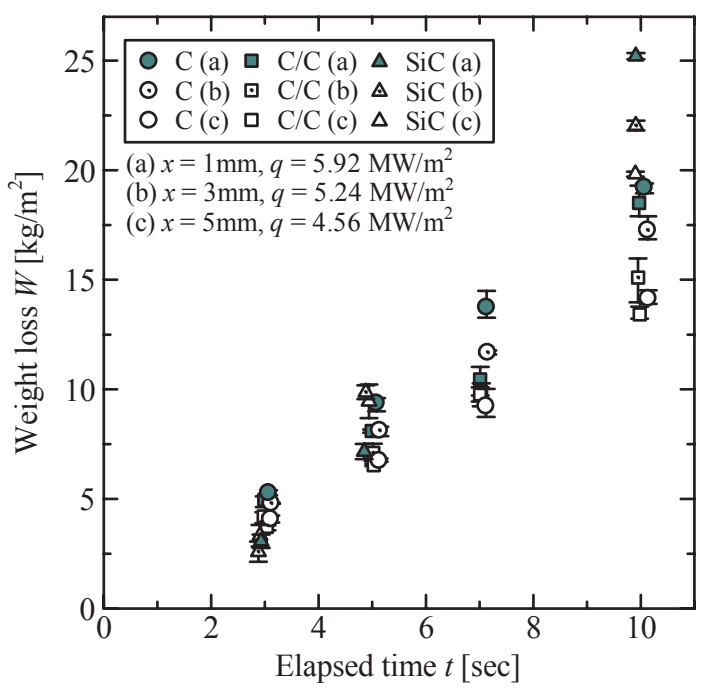

Fig. 7. Weight loss as a function of elapsed time.

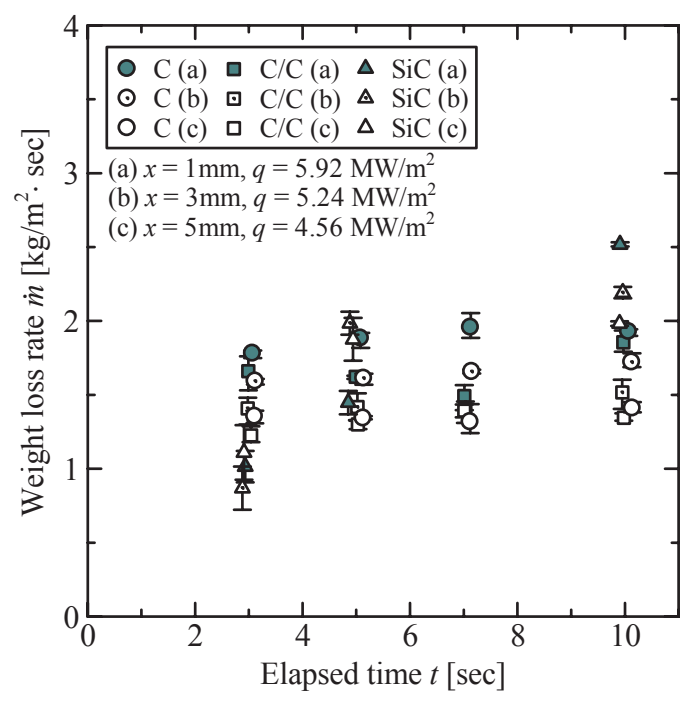

Fig. 8. Weight loss rate as a function of elapsed time.

where $\rho_{w}$ is the density of water, $C_{p}$ is the specific heat at constant pressure of water, $f$ is the flow rate of water, $\Delta T$ is the temperature rise of water, $A$ is the cross sectional area of the calorimeter. The error bars in Fig. 5 were determined from maximum and minimum data in all the measured heat flux data. The heat flux at the distance of $1 \mathrm{~mm}, 3 \mathrm{~mm}$, and $5 \mathrm{~mm}$ from the nozzle exit were $5.92,5.24$, and $4.56 \mathrm{MW} / \mathrm{m}^{2}$, respectively, as seen in Fig. 5. Thus, the heat flux decreased fairly drastically with increase of the distance from the nozzle exit in the upstream region of the jet. Figure 5 shows that the temperature distribution was almost the same as the heat flux, though the data of temperature were very limited. Relationship between the temperature and heat flux of the air plasma freejet was shown in Fig. 6. It is apparent that the temperature and the heat flux had a linear-shape relation. Using this relation, the temperature of the freejet was estimated even at the distance nearer than $20 \mathrm{~mm}$ from the nozzle exit. The temperatures thus estimated were about $7,500 \mathrm{~K}, 6,500 \mathrm{~K}$, and $5,500 \mathrm{~K}$ at the distance $1 \mathrm{~mm}, 3 \mathrm{~mm}$, and $5 \mathrm{~mm}$, respectively. 


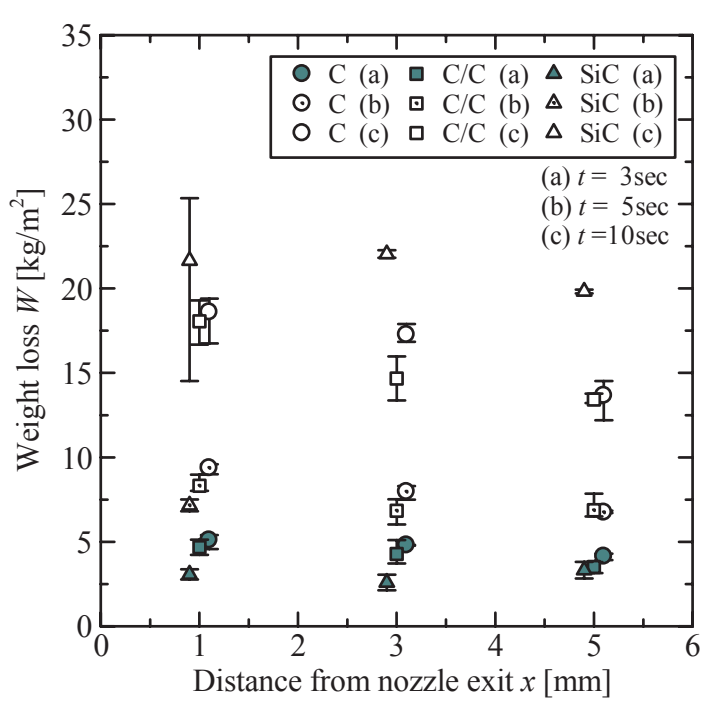

Fig. 9. Weight loss as a function of distance from nozzle exit.

\section{Results and Discussion}

\subsection{Ablation experiments}

Weight loss and weight loss rate were calculated from Eqs. (2) and (3), respectively.

$$
\begin{aligned}
& W=\left(w_{1}-w_{2}\right) / A, \\
& \dot{m}=W / t,
\end{aligned}
$$

where $W$ is weight loss per unit area, $w_{1}$ the weight of a test piece before experiments, $w_{2}$ the weight of the test piece after experiments, $A$ the cross-sectional area of the test piece before experiments, $\dot{m}$ the weight loss rate per unit area, and $t$ the elapsed time since the heating started.

Figure 7 shows the relationship between weight loss and elapsed time. Figure 8 shows weight loss rates calculated from the data in Fig. 7. The symbols (a), (b), and (c) in Figs. 7 and 8 show a difference in the distance between the 2nd-nozzle exit and the tip of a test piece, which means a difference in the cold wall heat flux of the plasma freejet, as mentioned above. The number of weight loss data for each test piece was 12 , namely measured for all of a combination of four elapsed times, 3, 5, 7, and 10sec, and three distances from the nozzle exit, 1,3 , and $5 \mathrm{~mm}$. It should be noticed that the data points of $\mathrm{C}$ and $\mathrm{SiC}$ in these figures are shifted from their appropriate elapsed times by $0.1 \mathrm{sec}$ and by $-0.1 \mathrm{sec}$, respectively, to avoid overlap of data points. Weight loss of all the test pieces increased with increasing elapsed time in Fig. 7. It is seen that the amount of weight loss of $\mathrm{C}$ in the short distance from nozzle exit was larger than in the longer distances, but the other materials had no such tendency. The weight loss rate of $\mathrm{SiC}$ increased much more steeply with elapsed time than the other materials. The amount of the increase from the elapsed time $3 \mathrm{sec}$ to $5 \mathrm{sec}$ was remarkable, and after that the increase seemed to calm down quickly. This indicates that longer time was required for the weight loss rate of $\mathrm{SiC}$ to be steady, as compared with $\mathrm{C}$ and $\mathrm{C} / \mathrm{C}$.

Figures 9 and 10 show the same results as in Figs. 7 and 8 except a horizontal axis of distance from nozzle exit. Data

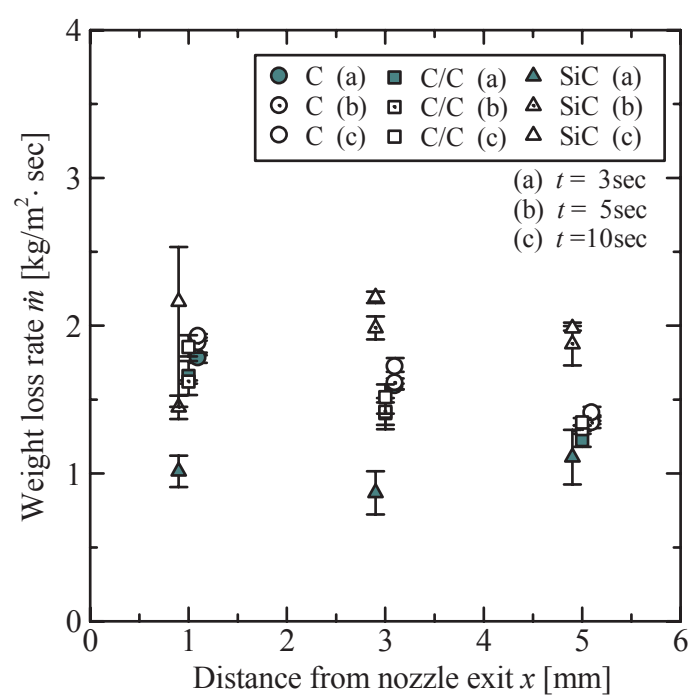

Fig. 10. Weight loss rate as a function of distance from nozzle exit.

points in Figs. 9 and 10 were shifted in the same way as in Figs. 7 and 8. Weight losses of $\mathrm{SiC}$ and carbonaceous material decreased with increasing distance in Fig. 9 with the exceptions for $\mathrm{SiC}$ at 3 and $5 \mathrm{sec}$. This was obviously caused by the fact that temperature and heat flux decreased with increasing distance from the nozzle exit in the present plasmajet ${ }^{9)}$. Results of $\mathrm{SiC}$ for the elapsed times of 3 and $5 \mathrm{sec}$ were almost independent of the distance. Judging from the experimental results for each test piece, weight loss of $\mathrm{SiC}$ was lower than the carbonaceous materials at the elapsed time of $3 \mathrm{sec}$, but the situation was reversed at 5 and $10 \mathrm{sec}$. Weight loss rates of the carbonaceous materials were almost the same if the distance was same. Those of SiC behaved differently for heat flux and elapsed time. Weight loss rates of the carbonaceous materials increased with a distance from nozzle exit.

\subsection{Surface observations with SEM}

Photographs and SEM images of ablated surfaces of the materials tested are shown in Figs. 11 and 12, respectively. All of the test pieces, shown as an example of the ablated surface, were heated for $5 \mathrm{sec}$ at the distance of $5 \mathrm{~mm}$ from the nozzle exit. Arrow in Fig. 11 indicates a flow direction. Shapes of the test pieces after experiments were roughly the same as shown in Fig. 11. Especially, carbon and carbon/carbon composite material were very similar to each other, mainly because shapes of both the test pieces before ablation experiments were the same. Whitish deposit covered with the ablated surface of $\mathrm{SiC}$, started at $3.2 \mathrm{~mm}$ from the tip of the test piece and ended at $5.7 \mathrm{~mm}$. It may be suspected as a cause for the difference in weight loss and weight loss rate between $\mathrm{SiC}$ and the other carbonaceous materials.

SEM images of a surface of the $\mathrm{SiC}$ test piece were taken along its center line. Positions, at which the images were taken, were marked with a box in Fig. 11. The SEM images are shown in Fig. 12. One can see a characteristic expression in each image. In Fig. 12 (A), very fine asperity can be seen, which seems due to attachment of very small solid particles from the upstream region on detailed observations. But, it can be said that the ablation of a region near the tip was resulted in very smooth surface. In Fig. 12 (B), material on the surface 
seems to have been solidified after temporally liquefied, as glasslike deposit is observed. This is confirmed in Fig. 12 (C). Ablated material near the tip of a test piece might be partly liquefied, swept downstream, and be solidified in the comparatively low-temperature region finally in a spherical shape. Such spherical particles are also observed in Figs. 12 (D) and (E), but the size of the particles is much smaller than those in Fig. 12 (C). Particles become reduced in size from the position (D) to (E), and then become unrecognized in (F). In Figs. 12 (D) and (E), blackish spots are also highly visible.

\subsection{Surface observations with optical microscope}

Figure $13(\mathrm{G})$ and $(\mathrm{H})$ are photographs taken by the optical microscope for $\mathrm{SiC}$ at the positions of (C) and (D) in shown in Fig. 11, respectively. Whitish deposit in the left area in Fig. 13 (G) corresponded to materials as the glasslike deposit in Fig. 12 (B). In the boxed area which corresponds to the upstream edge of spread of the whitish material in Fig. $13(\mathrm{G})$, one can see clearly spherical-shaped particles. It is estimated that these are the same as seen in Fig. 12 (C). Many tiny dimples are observed in Fig. $13(\mathrm{H})$. These correspond to the blackish spots in Figs. 12 (D) and (E).

\subsection{Chemical analyses with EPMA}

In Fig. 14, the positions where chemical analysis by EPMA was conducted are shown on the same SEM image of $\mathrm{SiC}$ as in Fig. 11 with open circles. There were 18 points in total, and the distance between adjacent circles was $0.5 \mathrm{~mm}$ in the most position. Results of chemical analysis are shown in Fig. 15. The horizontal axis is distance from the tip of test piece, and the vertical axis mole fraction of chemical species. Composition of $\mathrm{SiC}$ surface before ablation was found that the mole fraction of $\mathrm{C}$ was $46.1 \%$, O $0.5 \%$, and Si $53.3 \%$. Mole fraction of $\mathrm{O}$ was very high (about $80 \%$ ) in the whitish deposit area (from $3.2 \mathrm{~mm}$ to $5.7 \mathrm{~mm}$ ), and reduced to virtually $0 \%$ downstream. In this area, the mole fraction of Si was almost the same as the raw material, which meant the test piece was insusceptible to heating by the jet, and there was substantially no ablation beyond the whitish area. The whitish material was thought to be $\mathrm{SiO}_{2}$, though this prediction was based upon not so quantitative reason. Mole fractions of each chemical
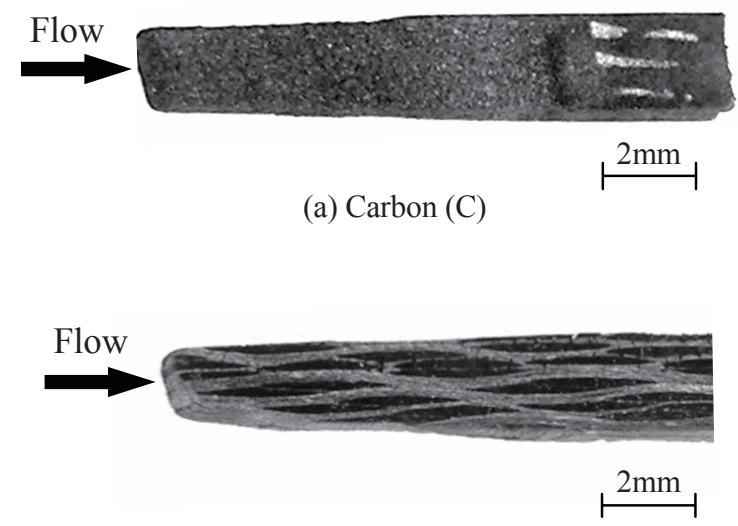

(b) Carbon/carbon composite material $(\mathrm{C} / \mathrm{C})$

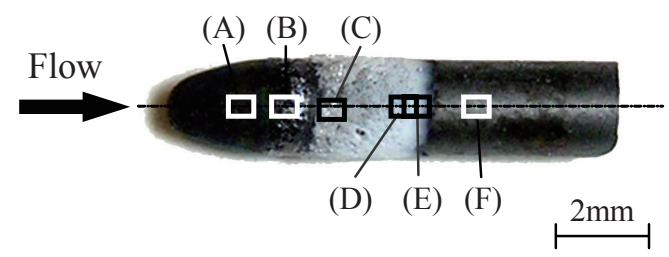

(c) Silicon carbide $(\mathrm{SiC})$

Fig. 11. Photographs of each material after ablation experiment.

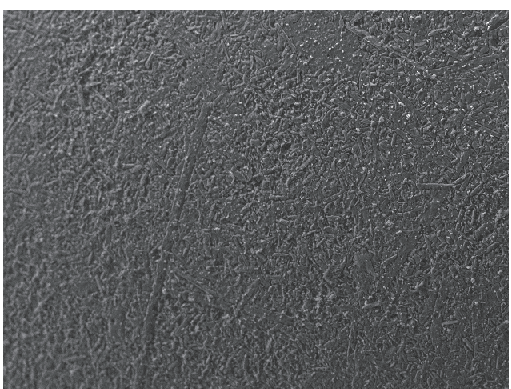

(A)

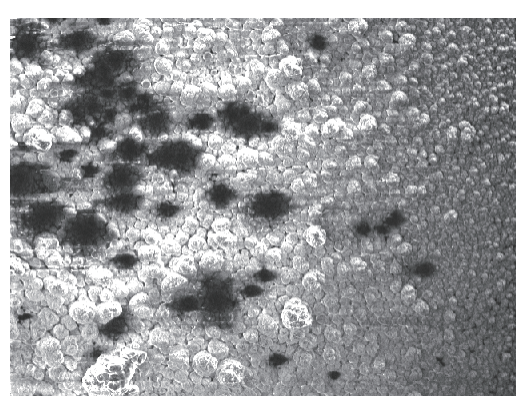

(D)

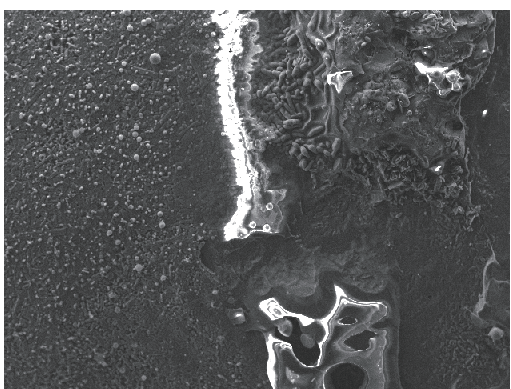

(B)

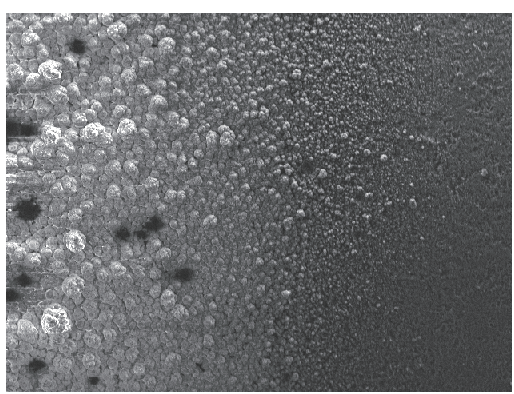

(E)

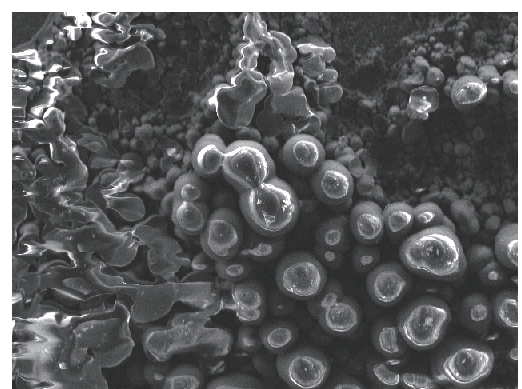

(C)

$100 \mu \mathrm{m}$

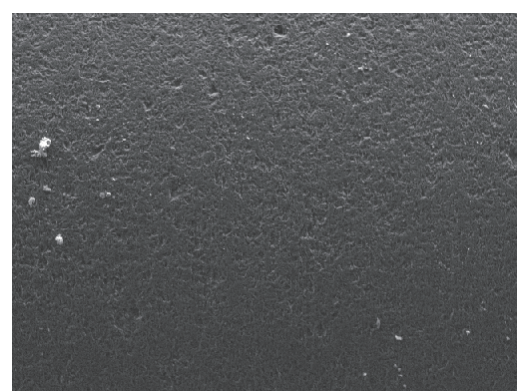

(F) $\quad 100 \mu \mathrm{m}$

Fig. 12. SEM images of SiC surface after ablation experiment. 

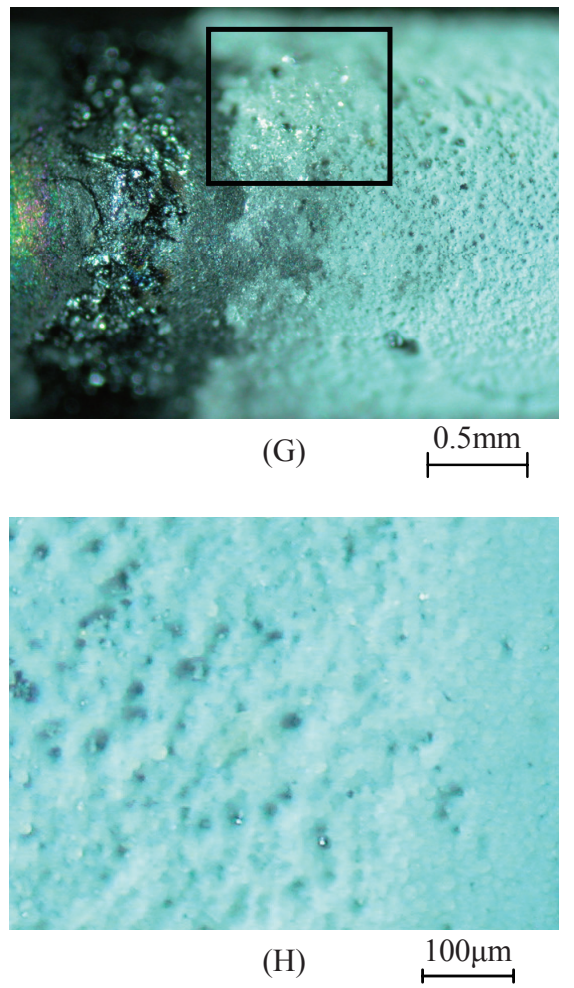

Fig. 13. Photographs of $\mathrm{SiC}$ surface after ablation experiment

species waved largely upstream of the whitish area (from $0 \mathrm{~mm}$ to $3.2 \mathrm{~mm}$ ) with converse changes in the $\mathrm{O}$ and $\mathrm{SiC}$ mole fractions. Considering the high mole fraction of $\mathrm{O}$, it was predicted that main material of the surface was $\mathrm{SiO}_{2}$ and that it was attached to the test piece surface nonuniformly. The cause for these phenomena has been unknown yet.

From the results of surface observations and chemical analyses as mentioned above, the process of production of the whitish material was estimated so that $\mathrm{SiC}$ decomposed to $\mathrm{Si}$ and $\mathrm{C}$ by the high-temperature jet, followed by reaction of $\mathrm{Si}$ and two O's generated by dissociation reaction of $\mathrm{O}_{2}$ in the jet, to make $\mathrm{SiO}_{2}$, i.e. whitish material.

\section{Conclusions}

In order to investigate the basic properties of advanced ceramics $\mathrm{SiC}$ as an ablation material, ablation experiments were performed for $\mathrm{SiC}, \mathrm{C}$, and $\mathrm{C} / \mathrm{C}$ in the air plasma freejet. Ablated SiC surfaces were also observed microscopically with SEM and optical microscope, and were analyzed chemically with EPMA. Main conclusions were deduced as follows.

(1) Weight loss rates of $\mathrm{SiC}$ required longer time to be steady as compared with $\mathrm{C}$ and $\mathrm{C} / \mathrm{C}$.

(2) Weight losses of $\mathrm{SiC}, \mathrm{C}$, and $\mathrm{C} / \mathrm{C}$ at the elapsed time 10 sec decreased with distance from the nozzle exit.

(3) Weight loss rates of $\mathrm{C}$ were almost the same as $\mathrm{C} / \mathrm{C}$ for all the heat flux. However, weight loss rate of $\mathrm{SiC}$ varied with the heat flux and the elapsed time.

(4) From the results of surface observations with SEM and optical microscope, and from the result of chemical analyses with EPMA, the whitish material attached to ablated SiC surface was estimated as $\mathrm{SiO}_{2}$.

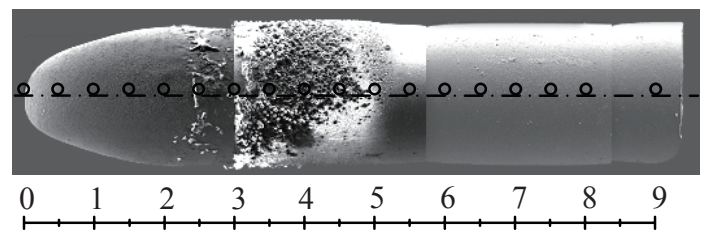

Distance from tip of test piece [mm]

Fig. 14. SEM image of $\mathrm{SiC}$ test piece and measuring positions on $\mathrm{SiC}$ surface after ablation experiment.

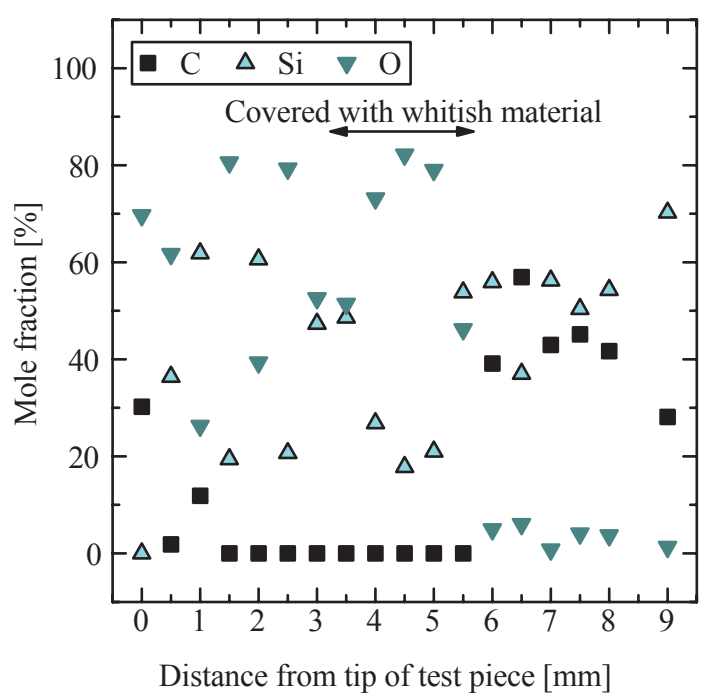

Fig. 15. Mole fraction profiles on SiC surface after ablation experiment.

\section{References}

1) Park, C.: Review of Chemical-Kinetic Problems of Future NASA Missions, I: Earth Entries, Journal of Thermophysics and Heat Transfer, 7-3 (1993), pp.385-398.

2) Metzger, J. W., Engel, M. J. and Diaconis, N. S.: Oxidation and Sublimation of Graphite in Simulated Re-Entry Environments, AIAA Journal, 5-3 (1967), pp.451-460.

3) Milos, F. S.: Galileo Probe Heat Shield Ablation Experiment, Journal of Spacecraft and Rockets, 34-6 (1997), pp.705-713.

4) Funatsu, M., Shirai, H. and Kasuya, K.: Radiative Characteristics of Carbonaceous Ablation Layers with Reflection Effects, JSME Int'l Journal, B, 44-3 (2001), pp.419-426.

5) Funatsu, M. and Shirai, H.: Reduction of Radiative Heating due to a SiC Ablation Layer, Proc. 24th Int'l Sympo. Shock Waves, 1 (2004), pp.221-226.

6) Ito, K., Funatsu, M., Shirai, H. and Takakusagi, F.: Ablation Experiments of Carbonaceous Materials with Micro-air Plasma-jet at an Atmospheric Pressure, Proc. 37th Fluid Dynamics Conference, (in Japanese), (2005), pp.97-100.

7) Ito, K., Funatsu, M., Shirai, H., Moteki, M. and Takakusagi, F.: Ablation Experiments of SiC-based Materials in Micro-air Plasma-jets at an Atmospheric Pressure, Proc. Japanese Sympo. Shock Waves, (in Japanese), (2006), pp.211-214.

8) Funatsu, M., Ito, K., Shirai, H., Moteki, M. and Takakusagi, F.: Heat-resistance Experiments of SiC-based Ceramics in High-temperature Air Plasma-jets, Proc. 25th Int'l Sympo. Space Technology and Science (Selected Papers), (2006), pp.750-755.

9) Shimada, K., Moteki, M., Funatsu, M., Shirai, H. and Takakusagi, F.: Heat-resistance Experiments of SiC-based Materials in Air Plasma Freejets, Proc. 40th Fluid Dynamics Conference, (in Japanese), (2008), pp.213-216. 